\title{
Perspectiva Relacional no Estudo do Processo de Trabalho em Saúde: Contribuição Para uma Nova Abordagem a Partir do Estudo da Prática do Nutricionista no Campo da Alimentação Institucional
}

\author{
A Relational Perspective in the Study of the Work Process in Health: A \\ Contribution to a New Approach Starting From the Study of the Practice of \\ the Nutritionist in the Area of Institutional Nutrition
}

\section{Solange V. Viana ${ }^{1}$}

VIANA, S. V. A Relational Perspective in the Study of the Work Process in Health: A Contribution to a New Approach Starting From the Study of the Practice of the Nutritionist in the Area of Institutional Nutrition. Cad. Saúde Públ., Rio de Janeiro, 11 (4): 616-620, Oct/Dec, 1995.

As part of the theoretical-conceptual review for a study of the practice of the nutritionist in an Industrial Complex, a discussion on the ways in which the notion of the work process has been dealt with and limits of such approaches were carried out. The study goes from a criticism of the classical marxist line, through Braverman and ends up with those authors who have stood out recently for their contributions to the theory of the work process, for example, Littler,

Thompson, Knights, Edwards and Burawoy. Using these contributions as starting point, the nutritionist's practice is examined from both the standpoints of the Production and the Gender Relatioships in a combined approach which, from the analytic point of view, try to complement each other. The study is concluded with a frame of reference the searchs through the nutritionist's practice meaning at industries to relativized both the independence of the professional subject and the structural determinism as it is portrayed in the literature produced here.

Key words: Work Process; Institutional Nutrition; Nutritional; Gender Relationship

\section{INTRODUÇÃO}

Os estudos sobre as práticas em saúde têm privilegiado a abordagem histórica, na qual a análise se coloca sob a perspectiva do processo de trabalho a partir dos seus três elementos constituintes clássicos: o objeto, os instrumentos e a atividade proposta, isto é, o próprio trabalho (Donnangelo \& Pereira, 1979; Gonçalves, 1979; Miranda, 1990; Silva, 1986).

Entretanto, no cenário da Sociologia do Trabalho, os recentes debates que têm ocorrido, apontam tanto os limites do processo de traba-

'Escola de Nutrição, Universidade Federal da Bahia. Rua Araújo Pinho, 32, Salvador, BA, 40110-150, Brasil. lho enquanto categoria geral, como têm possibilitado contribuições ao enrequecimento e ampliação dessa noção desenvolvida por Marx (Ramalho, 1991).

No esforço de incorporar, ao estudo da prática do Nutricionista no Pólo Petroquímico de Camaçari, pontos fundamentais deste debate, desenvolveu-se uma abordagem teórico-conceitual em três momentos: a) breve revisão bibliográfica da literatura crítica sobre a noção de processo de trabalho; b) revisão da produção brasileira, tomando o estudo de Gonçalves como o modelo explicativo balizador; c) sistematização dos elementos teórico-metodológicos desenvolvidos no estudo.

Este artigo traz uma síntese dos resultados desse processo, colocando as linhas gerais do 
debate atual no campo da Sociologia do Trabalho, a revisão crítica da produção teórica brasileira sobre processo de trabalho em saúde, os elementos centrais da abordagem teórico-conceitual por nós desenvolvida durante a investigação sobre a prática do Nutricionista.

\section{O DEBATE: ABORDAGENS E CRÍTICAS}

O conjunto de críticas dirigidas à noção clássica do processo de trabalho refere-se tanto ao modelo triangular desenvolvido por Marx - objeto, atividades e meios - quanto à noção de controle desenvolvida por Braverman (1987) em "Trabalho e Capital Monopolista", para discutir o modo como a gerência converte força de trabalho em trabalho real.

Para Edwards (apud Ramalho, 1991) o controle deve ser pensado não como algo em que apenas a gerência se envolve com os trabalhadores num papel puramente reativo, mas como um padrão que emerge num processo de luta. Fundamenta sua tese no fato de que a discussão sobre o controle e conflito não tem conseguido clarear a questão. Identifica uma tendência dos estudos a contrastar o controle dos capitalistas com a resistência dos trabalhadores fazendo-os negligenciar modos informais de controle. Segundo o autor, há um conflito de interesse básico (um antagonismo estruturado) entre capital e trabalho, todavia, torna-se necessário entender que há uma negociação da ordem, envolvendo arranjos informais de acomodação mútua. Esta compreensão, ao tempo em que ajuda a lidar com o problema da intencionalidade, serve para revelar a natureza multifacetada do controle, entendendo-o como um dos termos mais usados para contar como os trabalhadores são persuadidos a trabalhar.

Littler (1990) argumenta, em sua crítica, que o modo como Marx definiu o processo de trabalho limita-o ao relacionamento entre desempenho de tarefas, os objetos do trabalho e as ferramentas ou tecnologia, deixando por esclarecer o papel do controle. Para o autor, são várias as questões que permanecem sem resposta, entre as quais: será o processo de trabalho um conceito apropriado para a grande variedade de atividades econômicas e sociológicas que ocorrem no local de trabalho? Argumenta que não. Primeiro, há que se decidir o quanto da teoria econômica de Marx está necessariamente conectada a um estudo específico do processo de trabalho. Segundo, porque o conceito geral de processo de trabalho desenvolvido por Marx tem provado ser um instrumento insatisfatório para estudos empíricos e históricos. Assim, enfatiza a necessidade de uma nova categorização do processo de trabalho e sugere que este poderia ser analisado a partir de três elementos: a divisão técnica do trabalho e o planejamento do trabalho; a estrutura de controle; a relação de emprego.

Thompson (apud Ramalho, 1991) esclarece que os debates pós Braverman estabeleceram, embora sem consenso, um extenso terreno comum: o reconhecimento do papel crucial de mediação desempenhado pelos mercados de produtos e de trabalho; o efeito e o significado de várias formas de resistência operária; a necessidade de levar em consideração, mais seriamente, contextos históricos e econômicos específicos em vez de permanecermos no sentido amplo do capitalismo monopolista; e o significado do gênero moldando todos os principais aspectos do processo de trabalho que possibilita um novo ponto de partida para o debate.

Acredita, entretanto, que a crítica mais significativa até então, é a de que a ênfase, a priori, na contradição capital/trabalho na produção reproduz uma visão simplificada do controle e da fragmentação do trabalho, o que exclui e distorce a análise de certas práticas.

\section{PROCESSO DE TRABALHO EM SAÚDE: PRODUÇÃOTEÓRICA BRASILEIRA}

A produção teórica brasileira sobre o processo de trabalho em saúde tem no estudo de Gonçalves (1979) um marco que possibilitou o avanço para os estudos das diversas práticas em saúde.

Informado pelos estudos de Donnangelo \& Pereira (1979) e recebendo forte influência de Braverman (1978), o trabalho de Gonçalves Medicina e História; raízes sociais do trabalho médico - tem o propósito de discutir a Medicina na perspectiva de uma prática técnica e social. No plano formal, divide-se em duas partes: a pri- 
meira procura estabelecer ás características gerais da historicidade da prática médica a partir dos seus elementos constitutivos clássicos; a segunda, procura especificar as determinações mais concretas da prática tendo por referência a estrutura de historicidade configurada no modo de produção capitalista.

Para o desenvolvimento do estudo, Gonçalves adota como pilares fundamentais da sua construção teórica duas noções clássicas do pensamento marxista: 1) a análise do processo de trabalho a partir de três elementos: o objeto, os instrumentos e as atividades; 2) o modelo teórico-ideológico "classe em si"/"classe para si” (Przeworski, 1989).

À luz das recentes contribuições à análise do processo de trabalho, podem-se levantar algumas questões relativas à utilização dessas duas noções, com as quais Gónçalves buscou desenvolver um sistema explicativo:

- ao pensar o processo de trabalho médico a partir do modelo triangular clássico, a prática médica é confinada no âmbito do relacionamento entre desempenho de tarefas, objetos e instrumentos do trabalho, isolando-a do contexto das relações técnicas e sociais tecidas durante a sua realização;

- o modelo "classe em si"/"classe para si" entende os processos de formação de classes como uma transição necessária de "classe em si" para "classe para si". A "classe em si" é vista como uma categoria de indivíduos que possuem interesses comuns em virtude da posição que ocupam na infra-estrutura. A "classe para si” ficou sendo, na acepção sociológica do termo, a classe caracterizada pela organização e pela consciência de solidariedade. Com essa formulação, as relações econômicas são classificadas como condições objetivas e todas as outras relações consideradas como pertencentes à esfera de ações subjetivas (Przeworski, 1989).

Desse modo, a despeito do esforço de Gonçalves em superar o mecanicismo dessa noção procurando atribuir o mesmo peso à infra e à supra-estrutura na determinação das ações dos sujeitos da prática na organização dos interes- ses de classe, não consegue superar as amarras do modelo. Ou seja, se no plano teórico atribui o mesmo peso aos conteúdos objetivos e subjetivos na formação dos interesses de classe, no plano da análise recorre necessariamente à posição infra-estrutural de classe para problematizar questões como consciência e solidariedade.

Com essa formulação, Gonçalves traz para o centro da análise a questão da classificação, porque parte do entendimento das classes como agentes históricos, as classes que lutam e cuja luta - motor da história - é necessariamente determinada por posições objetivas.

Dessa perspectiva, depreende-se que, classificados como novos pequenos burgueses e tendo em comum os demais trabalhadores a mesma relação com os meios de produção e, portanto, os mesmos interesses objetivos, os trabalhadores médicos são apresentados como categorias e não como sujeitos. Ou seja, pessoas concretas aparecem apenas como portadoras de lugares, identificadas em termos de características objetivas.

O modelo também traz, de modo intrínseco, a problemática sobre o conflito de interesses materiais de curto prazo dos trabalhadores (assalariados) e capitalistas (apropriadores do excedente) (Przeworski, 1989). Fundamentado no suposto de que o capitalismo caracteriza-se pelo conflito objeto de interesses materiais de curto prazo, atribuídos aos indivíduos em sua condição de portadores de lugares objetivos, reduz a análise à simples dialética entre conflito e resistência. Considerando a resistência como uma constante e a consciência de classe como algo inevitável, o modelo não atribui importância às atitudes e motivações dos trabalhadores (Littler, 1990).

Com essa abordagem, Gonçalves, embora reconheça a importância de considerar na análise conteúdos objetivos e subjetivos, não consegue trabalhá-los. Sob as amarras do modelo, a identidade e a subjetividade dos sujeitos desaparecem, dentro dessa concepção de classe, na qual pessoas concretas aparecem homogeneizadas enquanto categoria analítica. Sob essa ótica, perde de vista o próprio sujeito, que, enquanto portador de uma dimensão subjetiva, age na construção de sua própria cultura, podendo ser, ora objeto de individuação, ora sujeito coletivo. 


\section{POR UMA NOVA ABORDAGEM: O RESGATE DO SUJEITO}

Com propósito de incorporar contribuições promovidas pelos recentes debates, o estudo sobre a prática do nutricionista, identifica nos instrumentos analíticos desenvolvidos por $\mathrm{Bu}$ rawoy (1985) e nos estudos de Gênero - sob o prisma das representações simbólicas e construções culturais -, os ângulos que melhor possibilitam apreender o processo de trabalho, além da organização social de tarefas.

Trata-se de uma abordagem "casada", em que o processo de trabalho do nutricionista é colocado sob o prisma das Políticas de Produção e Gênero, através do qual é possível visualizar tanto as relações sociais de trabalho como as relações sociais no trabalho.

Com essa concepção, Burawoy tenta trazer à luz a dimensão política da produção, fazendo a distinção analítica entre política de produção noção que pretende dar conta dos conflitos, lutas e tensões existentes no processo de trabalho - e regime fabril - conceito formulado para designar a reprodução do processo de trabalho, através da regulamentação de conflitos.

Desse modo, o conceito de política de produção inclui não só a organização social de tarefas como também o regime fabril, que enquanto estrutura, sofre as determinações das condições de reprodução da força de trabalho, da estrutura das relações industriais, do grau de controle das empresas sobre seus mercados, do tipo de processo de trabalho e da forma de gestão da força de trabalho.

Por outro lado, o instrumental analítico desenvolvido por Burawoy não consegue alcançar a problemática do gênero no processo de trabalho, apesar de, no plano teórico, pôr em evidência a identidade subjetiva. Este aspecto tem sido alvo de críticas por parte de Knights (1990: 313), por considerar que "o sexo talvez tenha uma influência significativa na formação das relações na produção".

Partindo dessas reflexões e considerando que os sujeitos da prática em nutrição pertencem, em sua maioria, ao sexo feminino, desconsiderar a sua identidade de gênero no estudo da sua própria prática significa ignorar um dos meios importantes para ampliar e enriquecer a ótica sob a qual o estudo se coloca.
Nesta concepção, a questão do gênero não se esgota nas relações de produção ou na produção. Assim como, a divisão sexual do trabalho, que recorta as relações no trabalho, não esgota a problemática do gênero, uma vez que se trata apenas de uma de suas várias dimensões. Portanto, considerando que as relações entre homens e mulheres são vividas e pensadas enquanto relações entre o que é definido como masculino e feminino, o uso do gênero como categoria analítica constrói, ao mesmo tempo, uma relação social-simbólica, sem estabelecer uma mecânica de determinação.

Assim sendo, a categoria gênero, quando articulada à divisão sexual do trabalho, abre possibilidades para pensar, além da qualificação, as "metamorfoses" do trabalho e o seu questionamento, a subjetividade no trabalho, as identidades no trabalho, o problema de igualdade e diferença e as formas contemporâneas da gestão e de políticas sociais (Souza-Lobo, 1991).

O fio condutor para essa abordagem "casada" - política de produção e gênero - está certamente em torno da própria noção de processo de trabalho, ou seja, as relações sociais estabelecidas entre homens e mulheres, à medida que transformam matérias-primas em utilidades.

\section{COMENTÁRIOS FINAIS}

A breve sistematização do percurso teórico, seguido para a elaboração do estudo sobre a prática do nutricionista no Pólo Petroquímico de Camaçari-Bahia, aponta os limites das abordagens correntes que privilegiam os aspectos estruturais da prática.

A perspectiva adotada sugere as imensas possibilidades de estudos sobre as práticas em saúde, a fim de uma maior aproximação das suas especificidades e tendências, a exemplo do processo de feminização da força de trabalho empregada no setor saúde (Médici, 1987).

Abordar esses processos, a partir do ângulo dos sujeitos enquanto sujeitos concretos de uma dada cultura em uma situação histórica específica, é o desafio que tentamos enfrentar. 
RESUMO

\section{VIANA, S. V. Perspectiva Relacional no}

Estudo do Processo de Trabalho em Saúde: Contribuição Para uma Nova Abordagem a Partir do Estudo da Prática do Nutricionista no Campo da Alimentação Institucional. Cad. Saúde Públ., Rio de Janeiro, 11 (4): 616-620, out/dez, 1995.

Como parte da revisão teórico-conceitual para o estudo da prática do nutricionista em um Complexo Industrial, desenvolve-se uma discussão sobre o modo como vem sendo abordada a noção de processo de trabalho e os limites de tais abordagens. $\mathrm{O}$ estudo parte da crítica ao enfoque marxista clássico, passa por Braverman e chega a autores que vêm se destacando por recentes contribuições à teoria do processo de trabalho, a exemplo de Littler, Thompson, Knights, Edwards e Burawoy. A partir das referidas contribuições, a prática do nutricionista coloca-se sob o prisma das Políticas de Produção e das Relações de Gênero, numa abordagem "casada", as quais, do ponto de vista analítico, buscam complementar-se. Conclui-se com um quadro de referências, que busca, através da finalidade da prática do nutricionista nestas indústrias, relativizar tanto a independência do sujeito profissional, quanto o determinismo estrutural presente na literatura sobre o tema em nosso meio.

Palavras-Chave: Processo de Trabalho; Alimentação Institucional; Nutricionista; Relações de Gênero

\section{REFERÊNCIAS BIBLIOGRÁFICAS}

BRAVERMAN, H., 1987. Trabalho e Capital Monopolista. $3^{\mathrm{a}}$ ed., Rio de Janeiro: Guanabara Koogan.

BURAWOY, M., 1985. The Politics of Production. Londres: Verso.

DONNANGELO, M. C. F. \& PEREIRA, L., 1979. Saúde e Sociedade. $2^{\underline{a}}$ ed., São Paulo: Duas Cidades.

GONÇALVES, R. B. M., 1979. Medicina e História; Raízes Sociais do Trabalho Médico. Tese de Mestrado, São Paulo: Faculdade de Medicina, Universidade de São Paulo.

KNIGTHS, D., 1990. Subjectivity, power and labour process, In: Labour Process Theory (D. Knights \& H. Willmott, eds.), pp. 297-335, Londres: The Macmilan Press.

LITTLER, C. R., 1990. The labour process debate; a theoretical review 1974-1988. In: Labour Process Theory (D. Knights \& H. Willmott, eds.), pp. 46-94, Londres: The Macmilan Press.

MÉDICI, A., 1987. A Força de Trabalho em Saúde no Brasil dos Anos 70; Percalços e Tendências. Textos de Apoio Planejamento I, Recursos Humanos em Saúde. Rio de Janeiro: Escola Nacional de Saúde Pública.

MIRANDA, C. R., 1990. Medicina do Trabalho; sua Prática e seu Mercado de Trabalho no Estado da Bahia. Tese de Mestrado, Salvador: Departamento de Medicina Preventiva, Universidade Federal da Bahia.

PRZEWORSKI, A., 1989. Capitalismo e SocialDemocracia. São Paulo: Companhia das Letras.

RAMAlHO, J. R., 1991. Controle, Conflito e Consentimento na Teoria do Processo de Trabalho; um Balanço do Debate. XV Reunião Anual da ANPOCS, Caxambu, MG. (Mimeo.)

SILVA, N. F., 1986. A Prática de Enfermagem na Bahia; Contribuição ao Estudo dos Profissionais de Enfermagem de Nível Superior. Tese de Mestrado, Salvador: Departamento de Medicina Preventiva, Universidade Federal da Bahia.

SOUZA-LOBO, E., 1991. A Classe Operária tem Dois Sexos; Trabalho, Dominação e Resistência. São Paulo: Brasiliense. 